Revista aSEPHallus de Orientação Lacaniana

Núcleo Sephora de Pesquisa sobre o Moderno e o Contemporâneo

ISSN $1809-709 \mathrm{X}$

\title{
Traço Unário: suporte da diferença significante
}

Tatiana Sousa Pinto

Mestre pelo Programa de Pós-graduação em Psicologia da Universidade Federal de Minas Gerais / UFMG, na Área de Concentração em Estudos Psicanalíticos.

E-mail: tatiana.sousa.p@gmail.com

\author{
Antonio Teixeira (orientador) \\ Professor adjunto / UFMG \\ Doutor em Psicanálise / Universidade de Paris VIII \\ Mestre em Filosofia / UFMG \\ Médico / UFMG. \\ E-mail: amrteixeira@uol.com.br
}

Resumo: Este artigo trata do conceito de traço unário conforme isolado por Lacan no Seminário 9 sobre a identificação, no qual ele destaca a principal propriedade desse traço: ser suporte da diferença. Em seguida, Lacan demonstra que essa propriedade é o sustentáculo das três teses minimalistas que servem de premissas para o estruturalismo adotado por ele, segundo Milner. O traço unário funda o conjunto dos significantes porque fornece sua propriedade fundamental. Mas, para isso, não é totalmente inscrito no simbólico. A teoria do signo de Saussure é aqui utilizada para esclarecer a especificidade da relação do simbólico com o real, que permite a emergência do traço unário como suporte da principal e única propriedade do significante: a inscrição da diferença.

Palavras chave: psicanálise; traço unário; significante; linguística; diferença.

Le Trait Unaire: support de la différence signifiante

Cet article traite de la notion de trait unaire comme isolé par Lacan dans le Séminaire 9 sur l'identification, dans lequel il met en évidence la principale propriété du trait: être le soutien de la différence. Il démontre, également, que cette propriété est le pilier des trois thèses minimalistes qui servent de prémisse pour le structuralisme adopté par Lacan, selon Milner (1996). Le trait unaire fonde tout le groupe de significants car, il fournit leur propriété fondamentale. Mais, pour cela, il n'a pas été entièrement inscrit dans le symbolique. La théorie du signe de Saussure est utilisée ici pour expliquer la spécificité de la relation du symbolique avec le réel, ce qui permet l'émergence du trait unaire comme le support de l'unique et principale propriété du signifiant l'inscription de la différence.

Mots-clés: psychoanalyse; trait unaire; significant; linguistique; difference.

\section{The Unary Trait: the support of the significant difference}

This article approaches the concept of unary trait as it has been singled-out by Lacan in his seminar about 'The Identification' in which he extracts its main property: being the support of difference. Later on, we demonstrate that this property is the mainstay of the three minimalist theses which serve as premises for the structuralism adopted by Lacan according to Milner (1996). The unary trait creates the set of signifiers because it provides them with their fundamental property. However, in order to do that, it cannot be fully inscribed on the symbolic. The Sign theorization by Saussure is then used to enlighten the specificity of the symbolic relation with the real, which allows for the emergence of the unary trait as the support of the main and only property of the signifier: the inscription of difference.

Key words: psychoanalysis; unary trait; signifier; linguistic; difference. 


\title{
Traço Unário: suporte da diferença significante
}

\author{
Tatiana Sousa Pinto \& Antonio Teixeira
}

O presente artigo é resultado de uma pesquisa de mestrado desenvolvida na universidade Federal de Minas Gerais sob a orientação do Prof. Doutor Antonio Teixeira. O objeto privilegiado desta pesquisa foi o conceito de Traço unário, cuja teorização encontra-se inicialmente no Seminário 9 (Lacan, 1961-1962/2003). O presente artigo pretende demonstrar a importância deste conceito para a definição do significante, sendo também um dos alicerces conceituais do estruturalismo adotado por Lacan. Por outro lado, gostaríamos de ressaltar que apesar de ser o suporte do conceito de significante, o que o coloca em estreita relação com o simbólico, o traço unário só pode conferir ao significante sua propriedade primordial, ser diferente de si mesmo, a partir de sua relação com um elemento exterior à lógica significante.

\section{As definições de traço unário}

A primeira pergunta que nos surge relativamente ao conceito lacaniano de traço unário decorre de sua aparição no Seminário 9, sobre a identificação. Qual a relação do traço unário com a questão da identificação? O termo identificação é, no mais das vezes, atrelado à relação especular do sujeito com a imagem, conforme explicitado no exemplo do grilo peregrino (Lacan, 1961-1962/ 2003, p. 27). Esse inseto, dependendo do encontro que tem com o seu semelhante, pode tomar a forma gregária ou solitária, sendo que, para cada uma, desenvolve caracteres morfológicos diferentes. Se há o imprinting com o semelhante, toma a forma gregária; se não, a forma solitária.

É em contraposição a esse modelo, relacionável a experiência do estádio do espelho, que Lacan apresentará a identificação relativa ao traço unário. Assim, ele nos introduz uma questão aparentemente inócua, a saber: porque admitimos que A é igual a A? Tal questão, entretanto, é por ele trabalhada desde o seminário das psicoses (Lacan, 1955-1956/1988, p. 172), no qual pergunta sobre o que nos possibilita diferenciar o dia da noite. Pressupõe que a compreensão do dia não é algo que venha da experiência. Um neonato que percorre os ciclos dos dias e noites não os reconhece naturalmente como antíteses. É preciso que algo interceda para que saiamos do ciclo noite e dia como algo irreconhecido. Para aceder à compreensão desse ciclo como uma alternância é necessário supor a ausência do dia. O dia e a noite são tomados, desde muito cedo, como códigos significantes, que só funcionam em pares de opostos quando se admite um ponto de negatividade. Portanto, antes de falar que $A$ é $A$, é preciso primeiro admiti-los como diferentes, já que, não sendo isso um pressuposto, inexistiria a necessidade de igualá-los em seguida. Ou seja, a identificação pressupõe uma diferença, sendo esta a propriedade principal do significante, conforme iremos expor mais abaixo. É, portanto, a alienação do humano ao significante que permite que ele perceba a diferença e opere com ela, podendo, inclusive, em seguida, preconizar a existência de igualdades. 
Diríamos, nesse sentido, que a identificação tem relação com traço unário na medida em que ele é o precipitador da diferença. Esse precipitador é o que propicia os eventos exclusivamente humanos, o que Lacan deixa claro ao retomar o exemplo de sua cadela. A tal cadela nunca se engana, ela sempre toma Lacan por Lacan, "contrariamente ao que acontece ao homem enquanto falante, ela não me toma jamais por um outro" (Lacan, 1961-1962/2003, p. 41). A cadela pode identificar automaticamente as duas aparições de Lacan, pois elas nunca foram diferentes. É nesse sentido que Lacan nos diz que "a identificação não tem nada a ver com a unificação. Somente a distinguindo desta é que se pode dar-lhe, não somente seu destaque e essência, como suas funções e suas variedades" (1961-1962/2003, p. 49). Se radicalizamos esse argumento, diríamos inclusive que não há identificação a não ser simbólica, no sentido de que não há que se identificar o que nunca foi distinto.

O humano, portanto, interceptado pela linguagem, percebe as diferenças e só a partir de uma crença pode igualá-las. Seria o mesmo que dizer que o humano, alienado ao Outro, tem acesso à alteridade, ao que é radicalmente diferente. Como consequência, as identificações por ele estabelecidas não são sempre óbvias, já que dependem de um julgamento, uma fé. Lacan demonstrará que é esse mecanismo que permite o advento da transferência, que consiste em tomar um por outro. Para exemplificar, Lacan (1961-1962/2003, p. 47) retoma uma lenda Céltica em que o senhor de uma fazenda morre. Após esse acontecimento, um empregado vê um ratinho que passeia pelo campo. O servo o segue e vê que o rato vai ao celeiro. Tal servo interpreta que o senhor era aquele ratinho que passeou pela propriedade para despedir-se, e tem a confirmação disso, segundo a lenda, a partir da aparição do espírito do senhor que diz ter estado no rato. É muito premente esse efeito da identificação que pode aproximar duas manifestações tão distintas, a do amo e a do ratinho que vaga sem motivo, o que é colocado na dependência de uma sofisticação tipicamente humana. Assim, para Lacan, a identificação simbólica serve para ler o fenômeno em questão percebendo-o como especificamente humano e complexo. Isto contraria vivamente a avaliação de um teórico - Levy-Bruhl (conforme citado por Lacan, 1961-1962/2003, p.47) - que acredita que essa lenda é resultado de uma "mentalidade pré-lógica" e de um pensamento místico.

Há uma outra ilustração escolhida por Lacan (1961-1962/2003, p. 87), que permite perceber como a premissa da diferença é preponderante em relação a da igualdade. Trata-se do exemplo da fada Morgana, mencionado por John Stuart Mill: ao perceber que a casa de seus adoradores fora marcada por terem sido condenados a um flagelo, Morgana marca todas as outras casas da mesma forma; assim, todas teriam o mesmo símbolo e não seria possível distinguir qual é qual. Portanto, os malfeitores não saberiam qual casa atingir. Lacan, entretanto, prefere a versão de um outro autor, Gardner, que teria repensado esse exemplo dizendo que, se Morgana quisesse de fato ter escondido os signos que distinguiam as casas, ela teria que ter marcado todas as casas com os mais diversos signos de modo a tornar inviável distinguir qual deles seria o certo já que todos eram igualmente distintos. Ou seja, aqui a qualidade basal é a distinção e não a igualdade. 
Dissemos que todos esses fenômenos simbólicos dependem da percepção da diferença, logo atrelada a um início mítico. Para compreender esse "saltar aos olhos" um destacamento da diferença, recorreremos novamente a Lacan (1961-1962/2003, pp. 51-65). Ele estava na presença de um achado arqueológico que era exposto em meio a outros. Tratava-se de um osso, uma costela, na qual havia pequenos traços em forma de bastão, como se fossem ranhuras. Lacan tratou essas ranhuras como consequência do fato de que certa experiência, no cotidiano de nossos antepassados, se tornara mais proeminente que as outras e foi preciso marcá-la. Diríamos ter sido um fato que exerceu um corte em relação ao rotineiro. Entretanto, seria preciso notar que os registros no osso, que se devem ao relevo dado a tal experiência, diferem radicalmente da aparição pictografada de bisões ou de qualquer outro tipo de reprografia muito comum em cavernas e sítios onde viveram homens primitivos. Esse registro mínimo, um pequeno traço, não guarda nada da experiência da qual é a marca, não tem nenhuma qualidade, imagética ou não, referente àquilo que inscreve. É "a redução extrema, a seu propósito justamente, de todas as ocasiões de diferença qualitativa" (Lacan, 1961-1962/2003, p. 59). Temos em ambos os casos um registro, mas a diferença é gritante entre eles, pois em um dos registros, aquele que elimina a qualidade, é possível supor o surgimento da possibilidade do significante. É radical a ênfase posta por Lacan na qualidade do traço no que se refere a marcar o evento enquanto distintivo, a permitir "apreender o paradoxo da alteridade radical" (1961-1962/2003, p. 75), sendo que é esse afastamento da qualidade que permite que ele seja "tanto mais distintivo quando está apagado de tudo o que ele distingue" (1961-1962/2003, p. 75). Lacan supõe uma vocação humana para a utilização do significante como consequência da descoberta do registro sem qualidade: "Há no material pré-histórico uma infinidade de manifestações de traçados que não tem outro caráter senão serem, como esse traço, significantes e nada mais" (1961-1962/2003, p. 90).

Temos assim o traço unário tomado como suporte da diferença significante. Seria dizer que a propriedade primordial do significante em ser distinto de todos os outros, se baseia na "originalidade que carrega do traço, digamos, da serialidade que ele comporta, traço discreto, quer dizer, de corte" (Lacan, 1961-1962/2003, p. 28). O traço unário é o que constitui o conjunto dos significantes, "é o que tem em comum todo o significante, de ser sobretudo constituído como traço, de ter esse traço por suporte" (Lacan, 1961-1962/2003, p. 35). Assim, o fato de que um significante seja diferente do outro é dependente da noção do traço unário. Além disso, se a principal característica do significante é a sua propriedade de diferir de seu par, então, o fundamental do significante é o traço unário.

Sublinhamos, portanto, as duas características básicas do traço unário conforme as apresentamos até aqui:

1) Funciona como suporte da diferença significante;

2) Implica que aquilo que foi registrado perca toda a qualidade que o definia. 
O traço unário é, portanto a condição de existência do significante. Assim, surpreendentemente, o que parece uma banalidade, ou seja, uma propriedade simples "por não ser mais do que ele é, ou seja, um puro traço distintivo" (Teixeira, 1999, p. 117), é o que sustenta um dos conceitos mais fundamentais àquela que foi a primeira abordagem de Lacan ao ensino freudiano: o significante.

Para percorrer essa hipótese queremos retomar a teorização de Milner (1996) sobre a apropriação Lacaniana do estruturalismo, sistema do qual Lacan exportou o conceito de significante. Milner, ao dividir o ensino de Lacan, nos demonstra que, em seu primeiro momento, o "primeiro classicismo lacaniano", Lacan importou do estruturalismo linguístico os pressupostos epistemológicos para teorizar sobre a psicanálise. O sistema estruturalista, por sua vez, surge no estudo da linguística quando essa disciplina emancipa-se dos estudos anteriores sobre a linguagem e toma a língua como um objeto científico. Para Milner, o estruturalismo linguístico se aproxima em alguns pontos do ideal de ciência que se instaura desde a antiguidade. Assim sendo, Milner se utiliza de três teses para demonstrar como o estruturalismo se constrói como uma versão da ciência, tomando o objeto língua enquanto um objeto científico. Iremos apresentar esses três pressupostos epistemológicos, para em seguida defender que os três derivam da ideia de traço unário.

Apresentaremos o que seriam as três teses minimalistas:

1) um minimalismo da teoria: uma teoria ficará mais próxima do ideal da ciência na medida em que ela se impuser, para um poder descritivo máximo, o uso de um número mínimo de axiomas e de conceitos iniciais

2) um minimalismo do objeto: só conheceremos uma língua senos impusermos nela considerar apenas as propriedades mínimas que a tornam um sistema, decomponível em elementos eles mesmos mínimos;

3) um minimalismo das propriedades: um elemento de um sistema tem por únicas propriedades aquelas que são determinadas pelo sistema. (Milner, 1996, p. 79)

Daremos mais ênfase aos pressupostos epistemológicos que se baseiam respectivamente em um minimalismo de objeto e em um minimalismo das propriedades. Depois, comentaremos brevemente somente a primeira tese, que também não é longamente exposta por Milner (1996). Para compreender os dois últimos pressupostos epistemológicos, temos que ter em mente que eles servem para transformar a língua em um objeto para a ciência. Elas definem como a língua pode ser tomada como objeto cientíico.

A segunda tese é a que define o que é objeto para o sistema estruturalista. Ela postula que para que um objeto seja reconhecido pelo sistema ele tem que corresponder a uma definição apriorística do que é um objeto. Ou seja, um sistema qualquer precisa sempre definir os critérios ou as propriedades que o levam a considerar algo como um objeto legítimo ou pertinente ao campo. 
No estruturalismo linguístico, é fácil perceber qual é essa propriedade: a suposição da diferença. Isso significa que, se a propriedade fundamental de um elemento, para que ele seja considerado um objeto da linguística, é a diferença, o único objeto desse campo será o significante, que é definido como aquele que se difere de outro significante. O sentido, a intenção de comunicação, e outros temas clássicos da linguística só serão discutidos se puderem ser abordados pela via do significante, ou seja, se "pudermos ali considerar apenas as propriedades que se analisam, em última instância, como relações de diferenças" (Milner, 1996, p. 80).

A terceira tese é a que define quais serão as propriedades do objeto que interessam ao sistema. Esse pressuposto considera que um elemento só pode ter como propriedade a que for a ele atribuída pelo sistema. Inversamente, também só existe propriedade do sistema para o objeto por ele definido como tal. Essa tese comunga com a ideia de que, para que o simbólico funcione gerando ciência, ele não pode estar alicerçado no elemento perceptivo da realidade. A propriedade não vai do elemento para a teoria, como faria um empirista, mas sendo a diferença a única propriedade suposta ao sistema, ela é dada de antemão e não depende de nenhuma característica física ou perceptiva do elemento.

Esse terceiro postulado epistemológico pode ser mais bem entendido a partir do exemplo explorado por Lacan e citado acima: do osso com ranhuras. Neste exemplo, Lacan ressalta que, para que o traço no osso fosse tomado como uma forma de representação inovadora, ele não poderia guardar nenhuma característica qualitativa do evento que simbolizava. Assim sendo, aquilo que de fato permite escrever o fenômeno, fazer a notação do mesmo, não depende das características qualitativas, imagéticas, mas somente da propriedade que é dada ao elemento pelo sistema, ou seja, a característica de se distinguir.

Milner lembra-nos de que o estruturalismo é um método de redução das características sensíveis assim como o faz a física. A física persegue esse propósito ao dizer que um objeto não tem calor, rapidez, cor ou texturas. O objeto da física terá somente a característica dada a ele pela disciplina. As propriedades do objeto são aquelas que podem ser notadas como uma matemática guardando a possibilidade de ser relacionada a outras características e constantes. $O$ estruturalismo, enquanto filiado a um ideal de ciência também performa o mesmo movimento, só permite guardar de um fenômeno aquilo que se comporta em termos de significante. Assim há uma matematização do fenômeno, mas ela é reinterpretada, pois no estruturalismo é compreendida como "uma dissolução não quantitativa do qualitativo" (Milner, 1996, p. 75).

Esses dois pressupostos epistemológicos em conjunto permitem ao sistema estruturalista acessar fenômenos provenientes da "literatura (sua estrutura compositiva), da filosofia (seu alicerce epistêmico), da história (sua démarche), da antropologia (o mito ou as estruturas de parentesco), da psicanálise (o inconsciente), etc.(...), aplicando a elas uma mesma adjetivação" (Souza \& Couto, 2013). Por isso, conforme ressaltam Souza e Couto (2013), todos os campos de conhecimento podem ser lidos a partir da ideia deque são pertinentes ao campo da linguagem. 
Concluímos então que ambas as teses que sustentam o estruturalismo linguístico se baseiam:

1) Na ideia de que o sistema deve definir o que caracteriza o elemento;

2) No fato de que a propriedade do elemento que importa é tão somente aquela definida pelo sistema.

Se o sistema define que o que, no caso do estruturalismo linguístico, o que caracteriza o objeto é a suposição da diferença, da qual o traço unário é suporte, temos que a segunda define que essa é a única propriedade que um elemento precisa ter para ser pensável. Doravante, por essas duas teses, percebe-se que a ideia de traço unário é o suporte do sistema estruturalista, porque é o suporte da diferença. Queremos ressaltar que o intuito de toda nossa incursão ao texto de Milner foi deixar claro que aquilo que funda o estruturalismo é a distinção que o conceito de traço unário vem sustentar. Milner respalda-nos numa fórmula lapidar: "A linguística estrutural utiliza o que poderemos chamar diferença pura" (Milner, 1996, p. 82).

Em relação à primeira tese, Milner a define como um minimalismo de teoria, que repousa na ideia da axiomática antiga, segundo a qual a hipótese será tão superior quanto mais eventos explicar a partir de menos fórmulas. Citamos o argumento ao qual Lacan adere para com tal tese concordar:

Por que desde que se começou a fazer ciência - pois essas reflexões referem-se a algo bem diferente e a campos mais vastos que o de nossa experiência - exige-se a máxima simplicidade possível? (...) No princípio era o verbo, quer dizer No princípio era o traço unário. Tudo que é possível de ser ensinado deve conservar essa marca desse início ultra-simples (Lacan, 1962-1963/2005, pp. 30-31).

Seria dizer que esse ato divino, primeiro ato de criação, a distinção entre a luz e as trevas é o ato preponderante, ele gera uma simplicidade relacionada à simplicidade exigida da ciência. Neste ponto, se o simbólico é tributário do traço unário e apresenta grande fecundidade no âmbito da ciência, há uma assonância com o dito que Lacan recorta de Euclides para iniciar a lição V de seu seminário sobre a identificação, de 13 de dezembro de 1961 (Lacan, 1961-1962/2003, pp. 67-77): "que o número, ele, nada mais é que essa espécie de multiplicidade que surge precisamente pela introdução de unidades" (Euclides, elementos, 4, VII apud Lacan, 1961-1962/2003, p. 67).

Quisemos com essa citação ressaltar a proficuidade da noção de traço unário, como suporte do simbólico, em acessar o fenômeno, torná-lo inteligível, gerando, nos termos de Lacan "o quadro funcionante do pensamento" (1961-1962/2003, p. 70). Resumiríamos dizendo que o Um destacado, ao invés de reduzir, gera uma multiplicação do pensamento.

Dito isso, percebe-se então que toda a empreitada que visa encontrar a estrutura alcança o objeto no nível em que, mesmo que ele seja despojado de todas as suas características, esvaziado de todas as qualidades, ele ainda é pensável. Ao tomarmos as propriedades não quaisquer de 
qualquer estrutura, percebemos, na redução do fenômeno, o ponto limite em que ele ainda é pensável.

\section{0 traço unário em relação ao real}

Para tratar da relação do traço unário com o real, é preciso ter em mente a seguinte proposição: aquilo que funda o conjunto deve ser dele excluído. Se o traço unário é fundador do funcionamento significante, é por guardar relação com um ponto excluído do conjunto significante, mas garantidor de tal conjunto e seu organizador, por lhe conferir a propriedade principal, a de ser o suporte da diferença. Em outras palavras, quando se exclui do conjunto um ponto de pura negatividade e incompreensão, funda-se um sistema em oposição a esse ponto que conserva como característica principal, aquela de poder formar oposições.

Para expor de forma mais esquemática a dependência do traço unário em relação ao ponto de exclusão que não se deixa inscrever, do real, optamos por expor a semelhança entre o esforço de Lacan e o de Saussure para demonstrar de onde surge a ideia de distintividade.

Insistimos na leitura de Saussure, pois apesar de sustentarmos que o significante em Lacan não é o mesmo daquele teorizado por Saussure, a leitura de Milner (2003) nos permite vislumbrar que, quando se trata de verificar os pressupostos do conceito de significante, Lacan e Saussure ressaltam como propriedade primordial que ele seja capaz de impor descontinuidades, ou seja, de se colocar como unidade distinta. Ambos os autores pensam que essa propriedade de distintividade é relacionável com um início mítico.

Um outro argumento que justifica nossa incursão por esse autor é notar que esse inspirador de Lévi-Strauss e de tantos outros autores do estruturalismo, deu enorme importância ao conceito de diferença, sublinhando que tal propriedade não está relacionada a qualificadores que possam diferenciar um elemento de outro, mas à descontinuidade entre eles.

Desta feita, nossa estratégia será de explorar até que ponto o fundamento, o surgimento do que suporta da diferença é o mesmo em Saussure e Lacan, e a partir de que ponto tais teorias traçam rumos distintos.

Iniciando por Saussure, temos que, para esse autor, significado e significante são indissociáveis na formação do signo. Entretanto, a descrição de significado é bastante complexa, no mais das vezes, feita de forma negativa. Saussure diz que o significado é o conceito ou a ideia, mas o conceito é definido como aquilo que não é a própria coisa, nem a classe de coisas, nem a coisa conforme definida em um mundo ideal, gerando uma explanação demasiado confusa, no dizer de Ducrot, sobre "o que é que, positivamente, se deve entender por tal conceito" (Ducrot, 1984, p. 425).

Há que se perguntar por que Saussure mantém a ideia de significado. Isso pode ser entendido se observarmos que, na associação recíproca dos elementos do signo, a relação do significante, ou materialidade fônica, e significado, ou pensamento, mais além do que algo que 
eventualmente poderia gerar sentido, é o que, para Saussure, gera a delimitação das unidades enquanto propriedade primordial do signo:

[...] o papel característico da língua diante do pensamento não é criar um meio fônico material para a expressão da ideia, mas servir de intermediário entre o pensamento em o som, em condições tais que uma união conduza necessariamente a delimitações recíprocas de unidades. O pensamento caótico por natureza é forçado a precisar-se ao decompor-se. (Saussure, 2012, p. 159)

Ou seja, Saussure precisa supor o encontro entre dois heterogêneos para que surja um elemento que funcione como o que confere distintividade entre as ideias do pensamento e entre os sons da língua, e, para que haja essa diferenciação, algo dela deve se destacar como uma unidade. Anteriormente, o som e o pensamento são fluidos amorfos colocados em paralelo. É somente do encontro entre eles que se determinam mutuamente as divisões. É a união entre o som e o pensamento que gera a propriedade da distintividade da unidade. A metáfora eleita para demonstrar essa propriedade é aquela que supõe que som e pensamento, significante e significado, são como o vento e a água. Somente do encontro entre esses dois elementos heterogêneos é que se cria a onda como elemento destacado. Novamente se percebe a característica mais importante do signo linguístico: a distintividade.

Retomamos que, para Saussure, o pensamento é em princípio caótico: "nosso pensamento não passa de uma massa amorfa e indistinta" (Saussure, 2012, p. 158). É a junção entre pensamento e som que permite a precipitação do signo enquanto o elemento unitário que confere a propriedade de distintividade ao pensamento. Para Saussure:

Sem o recurso dos signos seriamos incapazes de distinguir duas ideias de modo claro e constante. Tomado em si, o pensamento é como uma nebulosa em que nada está necessariamente delimitado. Não existem ideias preestabelecidas, e nada é distinto antes do aparecimento da língua. (Saussure, 2012, p. 158)

Dali se nota o parentesco com a definição Lacaniana do traço unário como gerador da distintividade. Em Lacan, o traço unário é usado para "designar a função da unidade enquanto fator de coerência pelo qual alguma coisa se distingue daquilo que a cerca, faz um todo, um no sentido unitário da função" (Lacan, 1961-1962/2003, p. 68). A percepção do corte, da divisão, ou da diferença, é o que se destila como propriedade operacional: "a distintividade é cabalmente uma ação, e sobre essa ação se fundam os cortes reconhecidos como pertinentes" (Milner, 2003, p. 164, tradução nossa ${ }^{1}$ ). 
Por isso sustentamos que o signo de Saussure se aproxima da ideia lacaniana de significante mais do que se supõe geralmente. Entretanto é preciso notar, com Milner (2003, pp. 163-165), que o gesto de Lacan de separar o Significante e o Significado não pode ser minorado em sua importância.

Tal operação feita por Lacan aponta para a necessidade de supor um início mítico, do encontro entre dois heterogêneos, mas o traço unário só pode funcionar se não estiver em relação direta com algo indefinível. Se usarmos agora a terminologia psicanalítica, saberemos que podemos aproximar esse indefinível do real. Daí temos que a premissa do simbólico se funda em função do encontro do simbólico com o real, gerando a diferença enquanto tal. O traço unário é a marca dessa diferença que insiste no corte entre significante e significado. Por ele se indica onde se fixa o significante enquanto ponto de inscrição da letra, suscitando "esta noção de que o real, por mais que ele resista a se deixar conhecer, ele não pode nos trapacear" (Teixeira, 1999, p. 119).

Assim fica demonstrada a propriedade do traço unário: aquilo que funda e organiza, o que está no ponto mítico, deve se excluir do meio que ele organiza. Aquilo que é a relação necessária interna ao signo do qual provem a propriedade de distintividade tem que dele ser excluído, permanecendo apenas a marca, o traço deste real.

É neste ponto que a teoria de Lacan se destaca daquela de Saussure, pois, para o linguista, significante e significado são elementos indispensáveis à criação do signo, sendo este último a unidade que surge enquanto distinta de seu entorno a partir do encontro do significante com o significado. Para o psicanalista, entretanto, a propriedade da diferença somente advém se algo relativo ao conteúdo, ou ao significado, estiver completamente desligado do significante.

Se essa aproximação teórica se torna muito abstrata e de dura compreensão introduzimos a história da estratégia de um sábio legislador da Grécia Antiga, Sólon, que pode funcionar como uma alegoria, uma ilustração, que põe em relevo a mesma característica que queremos ressaltar: para fundarmos um sistema é preciso que ele guarde relação com um real mítico originário e, em seguida, há a necessidade um ato de apagamento. Se o traço unário é o que confere a propriedade principal do significante, sendo este o elemento indispensável ao estruturalismo adotado por Lacan, é preciso admitir que tal propriedade só se funda a partir de um apagamento, a exclusão de um elemento primordial, de grande importância no contexto.

Segundo essa alegoria, o personagem principal, Sólon, se depara com um momento de grande desestabilização na sua cidade, Athenas. Havia um embate entre os grandes donos de terra, Agathoi, que detinham o poder político, e os Kakoi, aqueles que nada possuíam e aos Agathoi estavam submetidos. Para resolver essa querela, Sólon se serve de uma figura sobre a qual era bem informado, a figura do fundador da cidade. Os fundadores das cidades gregas eram frequentemente descritos como figuras divinas de caráter mitológico, nobre e distinto, ou seja, eram homens cuja natureza era heterogênea àquela cuja civilidade criariam. Assim, a fundação da cidade estabelecia um marco inicial que permitia que cada cidade se diferenciasse, relacionando sua origem com um 
nome do passado ao entorno do qual se construía um monumento. Erigia-se um herói fundador que estabelecia "uma ponte entre uma fase pré-politica e uma fase humana civilizada" (Bignotto, 1999, p. 18).

A sabedoria de Solon, conforme formulado por Bignotto (1999), foi se colocar neste lugar de fundador, criando em torno de si um mito de distintividade em relação aos demais humanos. A partir deste lugar, enuncia as leis que organizariam o campo político, sem beneficiar nenhum dos lados políticos em demasia, nem mesmo o dos Agathoi, classe societária a qual pertencia. Entretanto, ao fazer isso, Solon se dá conta de que não poderia habitar essa cidade, visto que deste lugar que calcou para si, facilmente se tornaria um tirano. Assim, ele se retira da cena citadina, o que o torna um legislador solitário. A sabedoria Soloniana se demonstra em seu ato de apagar-se do campo que organiza.

Desta alegoria, percebemos que aquilo que funda, sendo um elemento heterogêneo ao fundado, precisa ser retomado para organizar o campo que institui, mas quando o é, deve ser apagado. Retomamos aqui que o traço unário tem essa dimensão heterogênea em função de seu parentesco com o real. Na medida em que enunciamos tal conceito, é possível perceber, como, a partir desse parentesco, o traço é o que fundamenta o funcionamento significante. Ou seja, a própria relação com o real é o que permite ao traço unário fundamentar a linguagem, o significante, mas somente a partir de um apagamento.

\section{Nota:}

${ }^{1}$ No original: [...] la distintividad es cabalmente una acción, y sobre esta acción se fundan los rasgos reconocidos como pertinentes.

\section{Referências Bibliográficas}

Bignotto, N. (1999, jun.). A Solidão do Legislador. In Kriterion, 99, 7-37.

Ducrot, O. (1984). O referente. Enciclopédia Einaudi: linguagem e enunciação (pp. 418-438). Porto: Imprensa Nacional - Casa da Moeda.

Lacan, J. (1961-1962/2003). O seminário, livro 9: a identificação. Recife: Centro de estudos freudianos do Recife (publicação interna, não comercial).

Milner, J. C. (1996). O primeiro classicismo Lacaniano. A Obra Clara (pp. 63-95). Rio de Janeiro: Zahar.

Milner, J.-C. (2003). El periplo estructural. Buenos Aires-Madrid: Amorrortu editores.

Saussure, F. (2012). O Valor Linguístico. Curso de Linguística Geral(pp. 158-160). São Paulo: Editora Cultrix.

Souza, M. F., \& Couto, L. F. (2013, jul. a dez.). O Estruturalismo em Jacques Lacan: da apropriação a subversão a corrente estruturalista do estabelecimento de uma teoria do sujeito inconsciente. Ágora (pp. 185-200). Rio de Janeiro: UFRJ. 
Teixeira, A. (1999). De deus como garantia ausente. O Topos Etico da Psicanalise (pp. 116-137). Porto Alegre: EDIPURCS.

Citacão/Citation: Pinto, T. S. \& Teixeira, A. (nov. 2015 a abr. 2016). Traço Unário: suporte da diferença significate. Revista aSEPHallus de Orientação Lacaniana, 11(21), 4-15. Disponível em www.isepol.com/asephallus. doi: 10.17852/1809-709x.2019v11n21p4-15.

Editor do artigo: Tania Coelho dos Santos.

Recebido/Received: 24/11/2015 / 11/24/2015.

Aceito/Accepted: 18/02/2016/02/18/2016.

Copyright: (c) 2013 Associação Núcleo Sephora de Pesquisa sobre o moderno e o contemporâneo. Este é um artigo de livre acesso, que permite uso irrestrito, distribuição e reprodução em qualquer meio, desde que o autor e a fonte sejam citados/This is an open-access article, which permites unrestricted use, distribution, and reproduction in any medium, provided the author and source are credited. 